\title{
PROTOCOLO DE MICROPROPAGAÇÃO DA GOIABEIRA SERRANA (Acca sellowiana (Berg) Burret)
}

\author{
FEIJOA (Acca sellowiana (Berg) Burret) MICROPROPAGATION PROTOCOL
}

\author{
Ana Carla Oltramari ${ }^{1}$, Lirio Luiz Dal Vesco ${ }^{2}$, Enio Luiz Pedrotti ${ }^{3}$, Jean-Pierre Henri Joseph Ducroquet ${ }^{4}$, \\ Rubens Onofre Nodari ${ }^{5}$, Miguel Pedro Guerra ${ }^{6}$
}

RESUMO

Visando ao desenvolvimento de um novo protocolo para a micropropagação da goiabeira serrana (Acca sellowiana (Berg) Burret) foram estabelecidos experimentos com segmentos nodais e microestacas. As citocininas 6-Benzilaminopurina $(B A P)$, Cinetina (Kin) e 2-Isopenteniladenina (2-iP) foram adicionadas ao meio de cultura Woody Plant Midium-WPM, visando à proliferação de brotações múltiplas dos genótipos 53B-7, 101, 529 e 152-12 x 458. As microestacas obtidas in vitro foram submetidas a diferentes períodos de indução, em $20 \mu \mathrm{M}$ de ácido indolbutírico $(A I B)$ e, posteriormente, transferidas para meio de cultura isento desse fitorregulador para a indução de raízes ou, alternativamente, submetidas a diferentes concentrações e tempos de exposição em AIB e transferidas para substrato. As citocininas empregadas não promoveram aumento na taxa de proliferação de brotos em relação à testemunha. O meio de cultura basal WPM, adicionado de Kin $(5 \mu M)$, proporcionou maior altura média dos brotos. Segmentos nodais do acesso 101 cultivados em meio de cultura WPM, isento de fitorreguladores, apresentaram maiores taxas médias de proliferação. Pulsos de seis dias com AIB $(20 \mu M)$ induziram uma maior taxa de enraizamento $(68,9 \%)$, um maior número médio de raízes (1,3 raízes) e raízes com maior comprimento médio $(5,6 \mathrm{~mm})$. Microestacas enraizadas ex vitro,

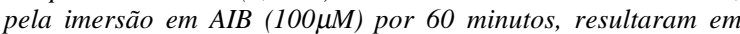
maior altura das plantas $(45,3 \mathrm{~mm})$, número de raízes secundárias (11,3 raízes), massa fresca (1069mg) e seca das raízes (282mg).

Palavras-chave: cultura de tecidos, organogênese, taxa de regeneração, enraizamento in vitro e ex vitro.

\section{SUMMARY}

The objective of this study was to establish a micropropagation protocol for Acca sellowiana (Berg) Burret. Nodal segments of in vitro cultivated plantlets of the genotypes $53 B-7,101,529$ and 152-12 $\times 458$ were inoculated in test tubes containing $15 \mathrm{~m} \ell$ of Woody Plant Medium-WPM solid medium supplemented with the cytokinins BAP, Kin, and 2-iP. For rooting purpose the microcuttings were submitted to different inductive periods of time with indolilbutiric acid-IBA (20uM), then transferred to a basal solid medium free of growth regulators, or alternatively to ex vitro substrate in a phytotron. The three cytokinins did not improve the multiple shoot regeneration rates when compared with the control. The highest shoot height was observed in the WPM medium supplemented with Kin $(5 \mu M)$. Nodal segments of the genotype 101, cultivated in WPM medium free of growth regulators showed higher regeneration rates than

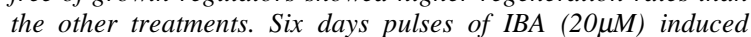
$68.9 \%$, of microcutting rooting as well the highest values for root (5.6mm) and length number $(1.3$ roots). Ex vitro rooting

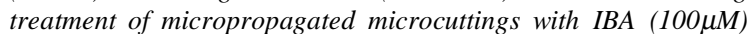
for 60min resulted in the highest values for plantlet height (45.3mm), secondary root number (11.3 roots), fresh (1069mg) and dry weight (282 $\mathrm{mg})$.of roots.

Key words: tissue culture, organogenesis, regeneration rate, in vitro and ex vitro rooting.

\section{INTRODUÇÃO}

A goiabeira serrana (Acca sellowiana (Berg) Burret), pertencente à família Myrtaceae, é uma espécie frutífera que se encontra nativa no sul do Brasil e no Uruguai. Em Santa Catarina, essa espécie ocorre espontaneamente em áreas com altitudes superiores a 1000 metros, mas ainda não é cultivada comercialmente, ao contrário do que ocor-

\footnotetext{
${ }^{1}$ Acadêmica do curso de Agronomia, Bolsista de IC/CNPq, CCA, Universidade Federal de Santa Catarina (UFSC).

${ }^{2}$ Engenheiro Agrônomo, Mestre, CCA, UFSC.

${ }^{3}$ Engenheiro Agrônomo, Doutor, Professor Adjunto IV do Departamento de Fitotecnia, CCA, UFSC.

${ }^{4}$ Engenheiro Agrônomo, Doutor, Pesquisador da Estação Experimental de Videira (EPAGRI).

${ }^{5}$ Engenheiro Agrônomo, Doutor, Professor Titular do Departamento de Fitotecnia, CCA, UFSC.

${ }^{6}$ Engenheiro Agrônomo, Doutor, Professor Titular do Departamento de Fitotecnia, do Centro de Ciências Agrária (CCA), UFSC, 88034001, CP 476, Florianópolis, SC. Email: mpguerra@cca.ufsc.br. Autor para correspondência. 
re em outras partes do mundo, especialmente na Nova Zelândia, Estados Unidos e Colômbia (DUCROQUET \& HICKEL, 1997).

Essa espécie apresenta porte reduzido, raramente ultrapassando $4 \mathrm{~m}$ de altura em condições de cultivo. A goiabeira serrana é uma espécie predominantemente alógama, de floração tardia que floresce nos meses de outubro-novembro quando não há mais riscos de geada e cuja polinização é assegurada em boa parte por pássaros frutívoros (DUCROQUET \& HICKEL, 1997). Em conseqüência, indivíduos com alta variabilidade genética são esperados na progênie, dificultando a fixação de características de interesse agronômico.

A propagação vegetativa convencional dessa espécie por estaquia apresenta baixa eficiência (DUARTE $\boldsymbol{e t} \boldsymbol{a l}$., 1992; FACHINELLO $\boldsymbol{e t} \boldsymbol{a l}$, 1992). A enxertia, processo atualmente utilizado para a implantação de ensaios de multiplicação, apresenta resultados aleatórios (FACHINELLO et al., 1992). Uma das causas é a contaminação por fungos, cujo desenvolvimento é favorecido pelo ambiente quente e úmido da casa de vegetação (ANDRADE \& DUCROQUET, 1992).

Tendo em vista essas limitações, técnicas de cultura de tecidos vegetais constituem-se em ferramentas que podem ser aplicadas para a micropropagação clonal massal de genótipos superiores e para a domesticação dessa espécie. Nesse sentido, a micropropagação por indução à embriogênese somática foi empregada com sucesso por GUERRA $\boldsymbol{e t}$ al. (1997) para dois genótipos de $\boldsymbol{F}$. sellowiana.

Estudos preliminares de micropropagação da $\boldsymbol{F}$. sellowiana, baseados na organogênese, foram desenvolvidos a partir de explantes de meristemas e folhas jovens (BHOJWANI $\boldsymbol{e t}$ al. 1987), além de meristemas caulinares e microestacas (DAL VESCO \& GUERRA, 1999). Os resultados obtidos por esses autores demonstraram baixas taxas de neoformação de gemas e altos índices de contaminação e oxidação, com ambas as fontes de explantes. Esses fatores indicam o grau de dificuldade e a baixa eficiência deste protocolo, embora suas aplicações práticas sejam mais imediatas, por permitir a propagação de genótipos já selecionados. Quando foram utilizadas plântulas germinadas in vitro para a obtenção de explantes, os resultados obtidos demostraram que o meio de cultura, contendo BAP e caseína hidrolizada, induziram a regeneração de brotações múltiplas a partir de segmentos nodais (BHOJWANI et al., 1987). BASSI \& COSSIO (1993) testaram diferentes formulações salinas para a micropropagação de $\boldsymbol{F}$. sellowiana e constataram a superioridade nos resultados, quando foi utilizado meio básico WPM (LLOYD \& McCOWN, 1980), isento de fitorreguladores.
Este trabalho foi desenvolvido em três etapas: fase de indução, fase de multiplicação com diferentes tipos de citocininas e seleção de acessos com maior potencial morfogenético in vitro e fase de indução ao enraizamento, in vitro e ex vitro, das microestacas cultivadas in vitro. $\mathrm{O}$ presente trabalho teve como objetivo estabelecer um protocolo de micropropagação baseado na organogênese direta, utilizando material vegetal de plântulas germinadas in vitro.

\section{MATERIAL E MÉTODOS}

O presente trabalho foi realizado nos anos de 1996 e 1997, no Laboratório de Fisiologia do Desenvolvimento e Genética Vegetal da Universidade Federal de Santa Catarina, Florianópolis, SC. Para a iniciação das culturas, utilizaram-se segmentos nodais de plântulas germinadas in vitro a partir de sementes dos acessos 53B-7, 101, 529 e 152-12 x 458 provenientes da EPAGRI - Estação Experimental de Videira, SC. As sementes foram inoculadas em frascos com capacidade de $300 \mathrm{~m} \ell$, contendo $30 \mathrm{~m} \ell$ de meio de cultura, composto pela formulação salina WPM (LLOYD \& McCOWN, 1980), com a adição de carvão ativado $(1,5 \mathrm{~g} / \ell)$. O meio de cultura basal foi acrescido de vitaminas de Morel (MOREL \& WETMORE, 1951), sacarose $(30 \mathrm{~g} / \ell)$ e geleificado com agar-agar $(6,5 \mathrm{~g} / \ell) . \mathrm{O} \mathrm{pH}$ foi ajustado com $\mathrm{NaOH}$ $(0,5 \mathrm{~N})$ para 5,8 antes da autoclavagem. As culturas foram mantidas em câmara de crescimento, com temperatura $\left(25 \pm 2^{\circ} \mathrm{C}\right)$, intensidade luminosa $\left(35,7 \mu \mathrm{mol} \mathrm{m} \mathrm{m}^{-2} \mathrm{~s}^{-1}\right)$, umidade relativa $(60 \pm 5 \%)$ e fotoperíodo (16h) controlados.

Para definir o tipo e a concentração dos fitorreguladores, adicionados ao meio de cultura basal e à escolha do acesso de maior potencial de proliferação de brotos, foram realizados dois ensaios.

Ensaio 1 - Plântulas do acesso 53B-7 tiveram seus eixos caulinares separados em câmara de fluxo laminar para a obtenção de segmentos nodais, que foram inoculados em tubos de ensaio (dois explante por tubo) contendo $15 \mathrm{~m} \ell$ de meio de cultura basal WPM suplementado com diferentes fontes de citocininas. As parcelas foram arranjadas segundo um delineamento fatorial $3 \times 4$, com 13 tratamentos: três fitorreguladores (BAP, Kin e 2-iP) em quatro concentrações $(0,05 ; 0,5 ; 5$ e $50 \mu \mathrm{M})$ e o meio de cultura basal livre de fitorreguladores, com três repetições, usando-se 10 segmentos nodais por unidade experimental (5 tubos de ensaio). Os dados de número de nós por plântula, número e altura de brotos (mm) foram coletados aos trinta dias após a inoculação. Quando necessário, os dados foram 
transformados e posteriormente submetidos à análise da variância e ao teste de separação de médias SNK $(5 \%)$. Os dados de número de nós por plântula e altura de brotos foram submetidos à análise de regressão (STEEL \& TORRIE, 1980), para avaliar a capacidade regenerativa de brotos em função da concentração das três citocininas testadas.

Ensaio 2 - Segmentos nodais dos acessos 53B-7, 101, 529 e 152-12 x 458 foram inoculados em tubos de ensaio, contendo $15 \mathrm{~m} \ell$ de meio de cultura basal WPM adicionado de Kin $(0$ e $5 \mu \mathrm{M})$. O delineamento experimental foi arranjado em um fatorial $5 \times 2$, onde foram testados cinco acessos e dois níveis de Kin, totalizando 10 combinações. Cada unidade experimental foi constituída de 10 segmentos nodais e arranjada em forma de blocos completamente casualizados, com quatro repetições. Os dados de número de nós por plântula e números de brotos por explante foram coletados aos trinta dias após a inoculação. Quando necessário, esses dados foram transformados e submetidos à análise da variância e ao teste de separação de médias (SNK a $5 \%$ ).

Microestacas originadas da proliferação de brotos do acesso 101 foram submetidas a dois ensaios, para promover a indução do sistema radicular:

Enraizamento in vitro - $\mathrm{Mi}$ croestacas contendo dois segmentos nodais $( \pm 2,5 \mathrm{~cm}$ de altura) foram submetidas a diferentes períodos de indução $(0,3,6,9$ e 12 dias), em meio de cultura WPM líquido adicionado de AIB $(20 \mu \mathrm{M})$. Após a indução, os explantes foram transferidos para meio de cultura basal WPM geleificado isento de auxina. Cada unidade experimental foi composta de cinco microestacas, arranjadas de forma completamente casualisada, com cinco tratamentos (cinco períodos de indução) e três repetições. Dados de percentagem de enraizamento, número e comprimento de raízes $(\mathrm{mm})$ foram coletados aos trinta dias de cultivo. Em seguida, esses dados foram submetidos à análise da variância, teste de separação de médias (SNK a 5\%) e à análise de regressão em função do tempo de exposição ao AIB.

Enraizamento ex vitro - Microestacas, contendo dois segmentos nodais $( \pm 2,5 \mathrm{~cm}$ de altura), provenientes do cultivo in vitro, foram transferidas para as condições ex vitro. Para promover a indução do sistema radicular, as bases das microestacas foram expostas em diferentes níveis de $\operatorname{AIB}(0,10$ e $100 \mu \mathrm{M})$ e diferentes períodos de indução (0 e 60 minutos).
Após a indução, essas microestacas foram transplantadas em bandejas alveoladas, contendo como substrato uma mistura de vermiculita e casca de arroz carbonizada, na proporção de 1:1 (v:v) e transferidas para sala de aclimatização em condições de alta umidade relativa do ar, temperatura $\left(28^{\circ} \mathrm{C}\right)$ e intensidade luminosa $\left(40 \mu \mathrm{mol} \mathrm{m} \mathrm{m}^{-2} \mathrm{~s}^{-1}\right)$ controladas, visando a evitar a desidratação das plântulas. Cada unidade experimental foi constituída de oito microestacas, arranjadas de forma completamente casualizada, com quatro repetições. Os dados de número de raízes primárias, raízes secundárias, massa fresca (mg), massa seca (mg) e altura das plântulas (mm) foram coletados aos trinta dias após a transferência. Quando necessário, esses dados foram transformados e submetidos à análise de variância e ao teste de separação de médias (SNK a 5\%).

\section{RESULTADOS E DISCUSSÃO}

\section{Efeito de diferentes citocininas na proliferação de brotações.}

A adição de citocininas ao meio de cultura basal WPM não proporcionou aumento na taxa de proliferação em relação à testemunha, seja em número de brotos ou em número de nós (tabela 1). No entanto, as taxas médias mais altas de proliferação

Tabela 1 - Efeito da adição de BAP, Kin e 2-iP $(0.05,0.5,5$ e $50 \mu \mathrm{M})$ e formulação salina WPM (Lloyd \& McCowm,1980), no número de nós por plântula, número de brotos e na altura de brotos do acesso 53B-7 de A. sellowiana, 30 dias após a inoculação. CCA/UFSC, 1996/97.

Tratamento $(\mu \mathrm{M}) \quad$ Número de Nós Número de Brotos Altura de brotos $(\mathrm{mm})$

\begin{tabular}{cccc}
\hline KIN 5,0 & $3,0 \mathrm{a}$ & $1,1 \mathrm{a}$ & $19,7 \mathrm{a}$ \\
testemunha & $3,0 \mathrm{a}$ & $1,1 \mathrm{a}$ & $14,0 \mathrm{abc}$ \\
BAP 0,5 & $2,8 \mathrm{a}$ & $1,1 \mathrm{a}$ & $15,3 \mathrm{ab}$ \\
2-iP 50,0 & $2,6 \mathrm{a}$ & $1,2 \mathrm{a}$ & $8,8 \mathrm{bcd}$ \\
KIN 0,05 & $2,2 \mathrm{ab}$ & $1,0 \mathrm{ab}$ & $11,8 \mathrm{abcd}$ \\
2-iP 0,05 & $2,1 \mathrm{ab}$ & $1,1 \mathrm{a}$ & $12,8 \mathrm{abcd}$ \\
BAP 5,0 & $2,1 \mathrm{ab}$ & $1,0 \mathrm{ab}$ & $6,4 \mathrm{cde}$ \\
2-iP 0,5 & $2,0 \mathrm{ab}$ & $0,9 \mathrm{ab}$ & $11,4 \mathrm{abcd}$ \\
KIN 0,5 & $2,0 \mathrm{ab}$ & $1,0 \mathrm{ab}$ & $10,6 \mathrm{abcd}$ \\
BAP 0,05 & $1,9 \mathrm{ab}$ & $1,0 \mathrm{ab}$ & $10,9 \mathrm{abcd}$ \\
2-iP 5,0 & $1,7 \mathrm{ab}$ & $0,8 \mathrm{ab}$ & $5,5 \mathrm{de}$ \\
KIN 50,0 & $1,0 \mathrm{~b}$ & $0,6 \mathrm{~b}$ & $3,7 \mathrm{e}$ \\
BAP 50,0 & $1,0 \mathrm{~b}$ & $1,0 \mathrm{ab}$ & 10,9 \\
\hline & & & 14,2 \\
Médias & 2,1 & 1,0 &
\end{tabular}

Média de três repetições. Letras indicam valores que diferem para o teste SNK (5\%).

${ }^{1}$ Dados transformados em $\log (\mathrm{x}+2)$ 
(3,0 nós/plântula) resultaram da adição de Kin $(5 \mu \mathrm{M})$ ao meio de cultura basal WPM e do tratamento isento de fitorreguladores (testemunha), aos 30 dias após a inoculação. Altas concentrações $(50 \mu \mathrm{M})$ de Kin e BAP revelaram os menores valores e diferem segundo o teste SNK (5\%), nesses parâmetros de proliferação, sugerindo um possível efeito fitotóxico dessas citocininas. Por outro lado, o 2-iP $(50 \mu \mathrm{M})$, usado na mesma concentração do BAP e Kin, por ser uma citocinina com menor estabilidade (GEORGE, 1993), permitiu o desenvolvimento de brotos de forma semelhante ao tratamento Kin $(5 \mu \mathrm{M})$ e testemunha.

Quanto ao parâmetro altura de brotos, o meio de cultura WPM adicionado com Kin $(5 \mu \mathrm{M})$ resultou em brotos, com um maior alongamento caulinar (19,7mm) (tabela 1).

A evolução das taxas de proliferação de brotos, em número de nós e altura, foi submetida à adequação dos modelos quadráticos (análise de regressão), para os dois parâmetros e fontes de citocininas (figura 1). Os altos valores dos coeficientes de determinação $\left(r^{2}\right)$ para os dois parâmetros testados e níveis de fitorreguladores expressam confiabilidade nas trajetórias, pois para esses sistemas consideram-se altos aqueles valores de $\mathrm{r}^{2}$, que ocorrem entre 0,5 e 0,9 (COMPTON, 1994). O cálculo da derivada dessas curvas sugere a existência de um nível ótimo de Kin, estimado em $22,8 \mu \mathrm{M}$, para a obtenção dos valores mais elevados no parâmetro número de nós por plântula e um nível de $23,7 \mu \mathrm{M}$ para a variável altura dos brotos, inferindo-se para esta concentração uma taxa média de proliferação de 4,4 nós por plântula e $34,3 \mathrm{~mm}$ de altura dos brotos (figura 1a e 1b). No entanto, como estes níveis de reguladores de crescimento não foram testados, a confirmação desses resultados necessita ser comprovada experimentalmente, testando-se várias concentrações entre $5 \mu \mathrm{M}$ e $50 \mu \mathrm{M}$ dessa citocinina.

Outros trabalhos também revelaram a necessidade de níveis mais elevados de Kin, em relação ao BAP, para a proliferação de brotos in vitro de Brassica juncea (SHARMA et al., 1990). Em Citrus aurantifolia e C. reticulata, maior proliferação de brotos foram obtidos como resposta à adição de 33,3 $\mu \mathrm{M}$ de BAP ao meio de cultura basal (PÉRESMOLPHE-BALCH \& OCHOA-ALEJO, 1997). Porém, neste trabalho, observou-se que concentrações elevadas de BAP causaram declínio no alongamento do caule e a morte dos explantes (figura 1b). Resultados semelhantes foram obtidos por FIGUEIRA et al. (1991) quando utilizaram elevadas concentrações de BAP na multiplicação in vitro de Theobroma cacao.

\section{Efeito dos genótipos na proliferação de brotos}

A análise de variância revelou diferenças significativas $(\mathrm{P}<0,01)$ entre os diferentes acessos testados, para os parâmetros número de nós e de brotos, 30 dias após a inoculação. As maiores taxas médias de proliferação de brotos (2,0 nós/plântulas) e número de brotos (1,0 broto/explante) foram obti-
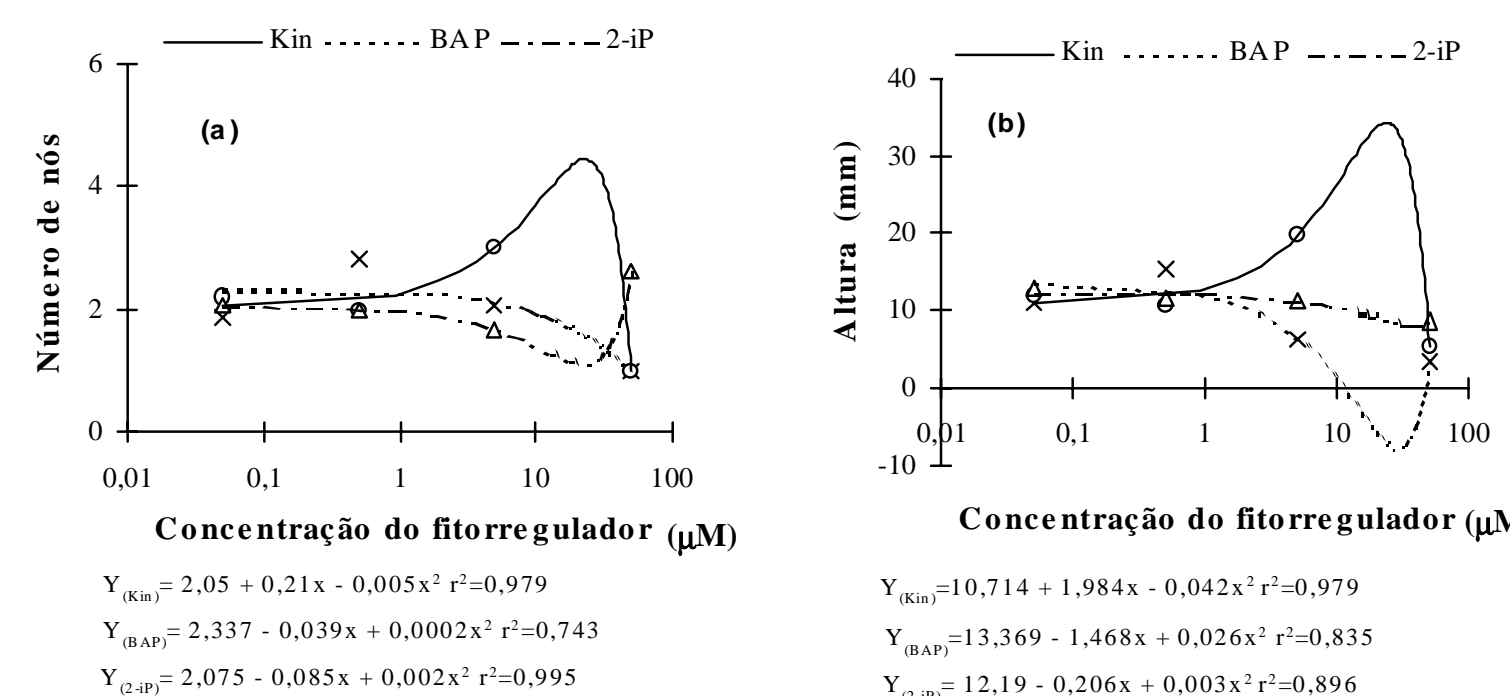

Concentração do fitorregulador $(\mu M)$

$Y_{(\text {Kin })}=10,714+1,984 x-0,042 x^{2} r^{2}=0,979$
$Y_{(B A P)}=13,369-1,468 x+0,026 x^{2} r^{2}=0,835$
$Y_{(2-\text {-iP })}=12,19-0,206 x+0,003 x^{2} r^{2}=0,896$

Figura 1 - (a) Número médio de nós por plântula, (b) altura de brotos, a partir de segmentos nodais do acesso 53B-7 de $\boldsymbol{F}$. sellowiana Berg, em resposta aos fitorreguladores BAP, KIN e 2-iP $(0,05,0,5,5,0$ e 50,0 $\mu \mathrm{M})$, adicionados ao meio de cultura basal WPM $(\mathrm{Lloyd} \&$ McCown, 1980), 30 dias após a inoculação. CCA/UFSC, 1996/97.

Ciência Rural, v. 30, n. 1, 2000. 
Tabela 2 - Taxa média de regeneração in vitro de brotos e nós por explantes dos genótipos 101, 529, 53B-7 e 152-12 x 458 de Feijoa sellowiana Berg., cultivados em meio de cultura WPM suplementado com Kin $(0$ e $5 \mu \mathrm{M}), 30$ (trinta) dias após a inoculação. CCA/UFSC, 1996/97.

\begin{tabular}{|c|c|c|c|c|c|c|}
\hline \multirow[t]{2}{*}{ Acesso } & \multicolumn{3}{|c|}{ Número de nós } & \multicolumn{3}{|c|}{ Número de brotos } \\
\hline & $\operatorname{Kin}(0 \mu \mathrm{M})$ & $\operatorname{Kin}(5 \mu \mathrm{M})$ & Média & $\operatorname{Kin}(0 \mu \mathrm{M})$ & $\operatorname{Kin}(5 \mu \mathrm{M})$ & Média \\
\hline 101 & 2,2 & 1,7 & $2,0 \mathrm{a}$ & 1,0 & 0,9 & $1,0 \mathrm{a}$ \\
\hline 529 & 1,7 & 1,0 & $1,4 \mathrm{ab}$ & 0,5 & 0,8 & $0,6 a b$ \\
\hline 53B-7 & 0,8 & 1,0 & $0,9 \mathrm{bc}$ & 0,7 & 0,4 & $0,5 \mathrm{~b}$ \\
\hline $152-12 \times 458$ & 0,8 & 0,3 & $0,5 \mathrm{c}$ & 0,6 & 0,4 & $0,5 \mathrm{~b}$ \\
\hline Média & $1,4 \mathrm{~A}$ & $1,0 \mathrm{~A}$ & 1,2 & $0,8 \mathrm{~A}$ & $0,5 \mathrm{~B}$ & 0,6 \\
\hline $\mathrm{CV}(\%)$ & & ${ }^{1} 18,4$ & & & ${ }^{1} 11,8 \%$ & \\
\hline
\end{tabular}

Média de quatro repetições. Letras minúscula na coluna e maiúsculas na linha, indicam valores que diferem para o teste $\mathrm{SNK}(5 \%)$.

${ }^{1}$ Dados transformados em $(\mathrm{x}+0,5)^{0,5}$.

das com o acesso 101 (tabela 2). Esses valores diferiram estatisticamente, segundo o teste SNK (5\%), daqueles obtidos com os acessos 53B-7 e 152-12 x 458. GUERRA et al. (1997) também observaram, na indução à embriogênese somática do acesso 101 de F. sellowiana, valores médios superiores nas taxas de indução, quando comparados com aqueles obtidos com o acesso 452. No presente trabalho, o meio de cultura WPM isento de fitorreguladores resultou em valores médios superiores e diferiu pelo teste SNK $(5 \%)$ dos valores resultantes da adição de Kin $(5 \mu \mathrm{M})$, para o número de brotos por explante e não diferiu para o número de nós por broto, confirmando os resultados obtidos no primeiro ensaio.

$O$ efeito de diferentes genótipos na multiplicação in vitro tem sido relatado por diversos autores. BHAGWAT et al. (1996) observaram diferenças significativas na taxa de 1996/97. proliferação de brotos, a partir de segmentos nodais, em oito diferentes genótipos de Manihot esculenta. $\mathrm{Na}$ micropropagação de cultivares de macieira, SRISKANDARAJAH et al. (1990) observaram diferentes taxas de proliferação de brotos adventícios. A utilização de diferentes genótipos para o estabelecimento de protocolos de cultivo in vitro possibilita obter resultados positivos para uso no melhoramento genético (BHAGWAT et al., 1996).

\section{Indução ao enraizamento das mi- croestacas}

Enraizamento in vitro Observa-se na figura 2 que pulsos de três dias na presença de AIB $(20 \mu \mathrm{M})$, em meio de cultura basal, foram suficientes para induzir $o$ enraizamento de $52,6 \%$ das microestacas (figura 2a). Essas microestacas apresentaram um número médio de 1,1 raízes/plântula (figura 2b) e um comprimento médio de $4,3 \mathrm{~mm} /$ raiz (figura 2c). Entretanto, o ponto máximo obtido pelas derivações das respectivas equações demonstrou que pulsos em torno de seis dias resultaram em taxas médias de enraizamento de $68,9 \%$

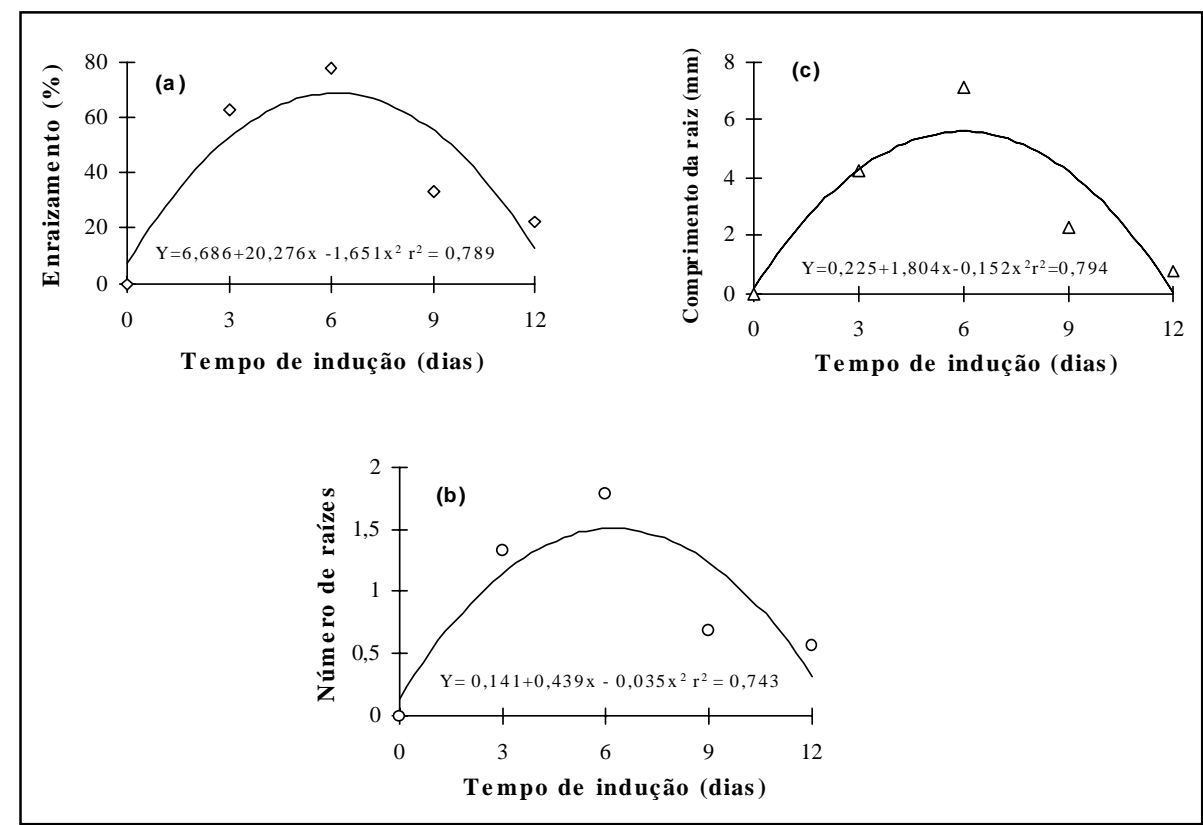

Figura 2 - Análise de regressão para o potencial de enraizamento in vitro de microestacas do acesso 101 de $\boldsymbol{F}$. sellowiana Berg. para: (a) percentagem de enraizamento, (b) número e (c) comprimento de raízes em função do tempo de indução ( $0,3,6,9$ e 12 dias) em AIB (20 $\mu \mathrm{M})$, adicionado ao meio de cultura WPM (Lloyd \& McCown, 1980), 30 dias após a indução. CCA/UFSC, 
(figura 2a), 1,5 raízes/plântula (figura 2b) e raízes com comprimento de $5,6 \mathrm{~mm}$ (figura 2c). Pulsos de AIB superiores a seis dias resultaram em sintomas de fitotoxidade às microestacas e diminuição da percentagem de enraizamento, do número e comprimento das raízes. A indução do enraizamento de brotos in vitro, com elevadas concentrações de auxina e a posterior transferência para meio de cultura isento de fitorregulador, possibilita obter os melhores resultados na formação de raízes (GEORGE, 1993).

Resultados semelhantes ao presente trabalho no enraizamento in vitro de A. sellowiana foram obtidos por BASSI \& COSSIO (1993). Esses autores verificaram que tratamentos de $\operatorname{AIB}(4,65 \mu \mathrm{M})$ e ANA $(5,38 \mu \mathrm{M})$, por um período de 30 dias em meio de cultura basal, resultaram em $77 \%$ dos brotos enraizados. O procedimento de pulsos com altas concentrações de AIB $(200 \mathrm{mg} / \ell)$ foi também utilizado para o enraizamento in vitro de Senna macranthera (SANTARÉM et al., 1996). Pulsos de cinco minutos em solução de AIB (1\%) demonstraram eficiência no enraizamento das microestacas de Purshia tridentata (EDSON et al.,
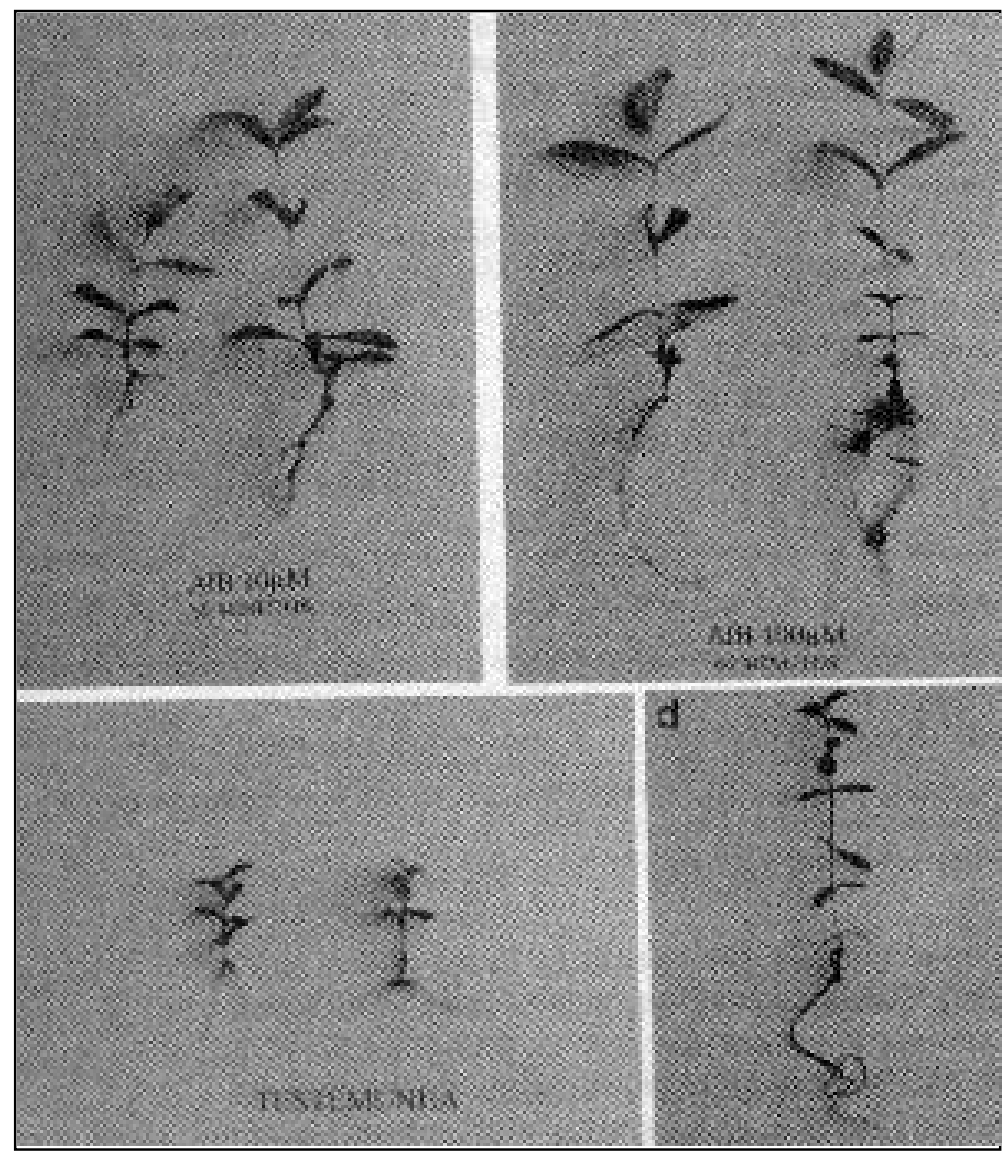

Figura 3 - Indução do enraizamento ex vitro de microestacas do acesso 101 de $\boldsymbol{F}$. sellowiana Berg após 30 dias. a) 60 min de indução em AIB $(10 \mu \mathrm{M})$, b) 60 min de indução em AIB $(100 \mu \mathrm{M})$, c) 60 minutos em água (testemunha), d) Microestaca enraizada in vitro em meio de cultura WPM (Lloyd \& McCown, 1980), isento de AIB. CCA/UFSC, 1996/97. 1997).

Enraizamento ex vitro -

Todas as microestacas transferidas diretamente para substratos formaram raízes e o índice de sobrevivência após a aclimatização foi de $92 \%$ (figura $3 \mathrm{a}, \mathrm{b}, \mathrm{c}$ ). Esses valores podem ser considerados excelentes para essa espécie quando comparados com os resultados observados por DUARTE $\boldsymbol{e t} \boldsymbol{a l}$. (1992), no enraizamento $\boldsymbol{e x}$ vitro de estacas semilenhosas da mesma espécie. Esses autores obtiveram uma taxa máxima de $31,6 \%$ das estacas enraizadas, quando utilizaram o AIB (5.000ppm) pelo método de imersão rápida. A maior taxa de enraizamento ex vitro de Purshia tridentata (72\%) foi obtida quando microestacas com 1,5 a $2,0 \mathrm{~cm}$ de comprimento foram submetidas a um tratamento de $0,1 \%$ de AIB em talco (EDSON $\boldsymbol{e t} \boldsymbol{a l}$., 1997). Microestacas de Pyrus calleryana revelaram $100 \%$ de enraizamento quando foram expostas por 24 horas ao AIB (30 e $50 \mathrm{mg} / \ell$ ) e imediatamente transferidas para substratos (PASQUAL \& LOPES, 1991).

No presente trabalho, as melhores respostas de indução ao enraizamento ex vitro das microestacas foram proporcionadas pelo tratamento com AIB $(100 \mu \mathrm{M})$ por um período de exposição de 60 minutos (figura 3b). Esse tratamento resultou em um maior alongamento caulinar, maior número médio de raízes secundárias $(11,3)$, maior massa fresca (1069mg) e massa seca $(282 \mathrm{mg})$ das raízes (tabela 3). Esses resultados diferem, para o teste SNK a 5\%, das demais combinações de AIB e dos tempos de exposição. As menores taxas de enraizamento foram observadas na testemunha, quando as microestacas foram transferidas diretamente para substrato (tabela 3). Na figura 3, pode-se observar a formação de raízes primárias e secundárias em resposta aos diferentes tratamentos ex vitro (figura $3 a, b, c)$ e o padrão de enraizamento in vitro a partir de segmentos nodais (figura 3d).

Os resultados obtidos neste trabalho per-

Ciência Rural, v. 30, n. 1, 2000. 
Tabela 3 - Efeito do AIB (0, 10 e $100 \mu \mathrm{M})$ e do período de indução (0 e 60 min) em microestacas de Feijoa sellowiana cultivadas ex vitro sobre a altura de plântulas $(\mathrm{mm})$, número médio de raízes primárias e secundárias e massa fresca e seca das raízes $(\mathrm{mg}), 30$ dias após a transferência. CCA/UFSC, 1996/97.

\begin{tabular}{|c|c|c|c|c|c|c|}
\hline \multicolumn{2}{|c|}{ Tratamento } & $\begin{array}{c}\text { Altura da } \\
\text { plântula (mm) }\end{array}$ & \multicolumn{2}{|c|}{$\begin{array}{l}\text { Número } \\
\text { de raízes }\end{array}$} & \multicolumn{2}{|c|}{$\begin{array}{c}\text { Peso das } \\
\text { raízes }(\mathrm{mg})\end{array}$} \\
\hline $\operatorname{AIB}(\mu \mathrm{M})$ & Tempo (min) & & Primária & Secundária & Fresco & Seco \\
\hline 100 & 60 & $45,3 \mathrm{a}$ & $1,8 \mathrm{a}$ & $11,3 \mathrm{a}$ & $1069 \mathrm{a}$ & $282 \mathrm{a}$ \\
\hline 10 & 60 & $31,4 \mathrm{~b}$ & $1,5 \mathrm{a}$ & $4,0 \mathrm{~b}$ & $296 \mathrm{~b}$ & $129 \mathrm{~b}$ \\
\hline 0 & 60 & $27,0 \mathrm{~b}$ & $1,5 \mathrm{a}$ & $3,4 \mathrm{~b}$ & $204 \mathrm{~b}$ & $98 \mathrm{bc}$ \\
\hline 0 & 0 & $22,4 \mathrm{c}$ & $1,4 \mathrm{a}$ & $0,8 \mathrm{~b}$ & $112 \mathrm{c}$ & $64 c$ \\
\hline \multicolumn{2}{|c|}{ Média } & 31,5 & 1,6 & 4,8 & 420 & 143 \\
\hline \multicolumn{2}{|c|}{$\mathrm{CV}(\%)$} & ${ }^{1} 4,3$ & 27,5 & ${ }^{1} 34,7$ & ${ }^{1} 6,5$ & ${ }^{1} 6,5$ \\
\hline
\end{tabular}

Média de 4 repetições. Letras indicam valores que diferem para o teste SNK (5\%).

${ }^{1}$ Dados transformados em $\log (\mathrm{x}+2)$.

mitem estabelecer um protocolo regenerativo baseado na organogênese direta, através da proliferação de brotos, para a micropropagação da A. sellowiana. Esse protocolo pode ser constituído por três fases: indução, multiplicação e enraizamento. A indução e a multiplicação de brotos podem ser realizadas em meio de cultura WPM, adicionado ou não de citocininas. O enraizamento das microestacas, originadas do cultivo in vitro, pode ser obtido por pulsos de AIB. Essas microestacas podem, então, serem transferidas para meio de cultivo isento de auxinas ou diretamente para substratos ex vitro. Nessa fase de enraizamento, quando foi utilizado o método de indução ex vitro em AIB $(100 \mu \mathrm{M})$ por 60 minutos, e a posterior transferência para fase de aclimatização, observou-se um aumento no número de raízes e um melhor estado funcional do sistema radicular. Esses resultados demostram que o enraizamento dos eixos caulinares obtidos in vitro pode ser feito em condições $\boldsymbol{e x}$ vitro, eliminando um dos estágios do protocolo regenerativo e, com isso, reduzindo o tempo e o custo de produção destas mudas. Segundo PREECE \& SUTTER (1991), o enraizamento in vitro é responsável por valores de 35 a $75 \%$ do custo total de micropropagação, aspecto que poderia tornar inviável a micropropagação da Feijoa sellowiana e de outras espécies.

\section{CONCLUSÃO}

O meio de cultura basal WPM isento de fitorreguladores induz as melhores respostas organo- genéticas, em termos qualitativos e quantitativos, na cultura de segmentos nodais in vitro de A. sellowiana. O meio de cultura basal WPM suplementado com as citocininas Kin, 2-iP e BAP, em concentrações variando de 0,05 a $50 \mu \mathrm{M}$, não proporciona uma taxa de proliferação in vitro de brotações superior àquela observada para segmentos nodais cultivados no mesmo meio de cultura basal isento dessas citocininas. O acesso 101 apresenta melhores respostas organogenéticas, revelando comportamento morfogenético genótipodependente. Pulsos de seis dias com AIB $(20 \mu \mathrm{M})$ em meio de cultura basal WPM proporciona as melhores respostas à indução ao enraizamento in vitro. Microestacas tratadas ex vitro com AIB $(100 \mu \mathrm{M})$, por 60 minutos, resultam em valores elevados de altura das plantas, número de raízes, massa fresca e massa seca das raízes.

\section{REFERÊNCIAS BIBLIOGRÁFICAS}

ANDRADE, E.R. de, DUCROQUET, J.P.H.J. Antracnose em goiabeira serrana. In: CONGRESSO IBEROAMERICANO, 1, CONGRESSO LATINO AMRICANO, 5, 1992, Montevidéu, Uruguai. Anais... Montevidéu, 1992. p.1.

BASSI, G., COSSIO, F. Risultati di ricerche sulla micropropagazione della feijoa (Feijoa sellowiana Berg.). L'informatore Agrario, Itália, v. 569, p. 79-80, 1993.

BHAGWAT, B VIEIRA, L.G.E, ERICKSON, LR Stimulation of in vitro shoot proliferation from nodal explants of cassava by thidiazuron, benzyladenine and gibberellic acid. Plant Cell, Tissue and Organ Culture, The Netherlands, v. 46, p. 1-7, 1996.

BHOJWANI, S.S., MULLINS, K., COHEN D. Micropropagation of Feijoa sellowiana Berg. Acta Horticulture, Belgium, n. 212, p. 69-76, 1987.

COMPTON, M. Statistical methods suitable for the analysis of plant tissue culture data. Plant Cell Tissue and Organ Culture, The Netherlands, v. 37, p. 2170242, 1994.

DALVESCO, L.L., GUERRA, M.P. Organogênese e micropropagação da goiabeira serrana (Feijoa sellowiana Berg). Revista Brasileira de Fruticultura, Jaboticabal, v. 21, n. 1, p. 60-64, 1999.

DUARTE, OR, FACHINELLO, J.C., SANTOS B.G.F. Multiplicação da goabeira serrana através de estacas semilenhosas. Pesquisa Agropecuária Brasileira, Brasília, v. 27, n. 3, p. 513-516, 1992. 
DUCROQUET, J.P.H.J., HICKEL, E.R. Birds as pollinators of feijoa (Acca sellowiana Berg). Acta Horticulturae, Belgium, v. 452, p. 37-40, 1997.

EDSON, J.L., WENNY, D.L. LEEGE-BRUSVEN, A Micropropagation of Antelope bitterbrush [Purshia tridentata (Pursh) DC.]. HortSience, Alexandria, v. 32, n. 2, p. 312314, 1997.

FACHINELLO, J.C., NIELKE, M.S., NACHTIGAZ, J.C. Propagação vegetativa da goiabeira serrana. Revista Brasileira de Fruticultura. Cruz das Almas, v. 14, n. 3, p. 233-236, 1992.

FIGUEIRA, A., WHIPKEY, A., JANICK, J. Increased $\mathrm{CO}_{2}$ and light promote in vitro shoot growth and development of Theobroma cacao. Journal of the American Society for Horticultural Science, Alexandria, v. 116, n. 3, p. 585-589, 1991.

GEORGE, E.F. Plant propagation by tissue culture. Part 1. The technology. 2. ed., Edington: Exegetics, 1993. 574 p.

GUERRA, M.P., PESCADOR R. ,DAL VESCO, L.L., et al. In vitro morphogenesis in Feijoa sellowiana: somatic embriyogenesis and plant regeneration. Acta Horticulturae, Belgium, v. 452, p. 27-35, 1997

LLOYD, G., McCOWN, B. Commercially-feasible micropropagation of mountain laurel Kalmia latifolia by use of shoot-tip culture. International Plant Propagation Society Proceedings. USA. v. 30, p. 421-427, 1980.

MOREL, G.M., WETMORE, R.H. Fern callus tissue culture Americam Journal of Botany, New York, v. 38, p. 41-143, 1951.

PASQUAL, M., LOPES, P.A. Efeitos da concentração e tempo de incubação em ácido indolbutírico sobre o enraizamento e posterior desenvolvimento de brotos de Pyrus Calleryana L. obtidos in vitro. Pesquisa Agropecuária Brasileira, Brasília, v. 26, n. 7, p. 975-980, 1991.

PÉRES-MOLPHE-BALCH，E，OCHOA-ALEJO， N. In vitro plant regeneration of mexican lime and mandarin by direct organogenesis. HortScience, Alexandria, v. 32, n. 5, p. 931934, 1997.

PREECE, J.E., SUTTER, E.G. Acclimatization of micropropagated plants to the greenhause and field. In.: DEBERGH, P.C., ZIMMERMAN, R.H. (eds.) Micropropagation - Technology and application. Dordrecht: Kluwer Academic, 1991, p. 71-93.

SANTARÉM, E.R., FERREIRA, A.G., AQUILA, A., $\boldsymbol{e t}$ al. Cultivo in vitro de Senna macranthera (Colladon) Var. Nervosa (Vogel) Ikwin \& Barneby. Hoehnea, São Paulo, v. 23, n. 1, p. 169-174, 1996.

SHARMA, K.K., BHOJWANI, S.S., THORPE, T.A. Factors affecting high frequency differentiation of shoots and roots from cotyledon explants of Brassica juncea 9L.) CZERN. Plant Science, Ireland, v. 66, p. 247-253, 1990.

SRISKANDARAJAH, S, SKIRVIN, R.M, ABU-QAOUD, H., KORBAN, S.S. Factors involved in shoot elongation and growth of adventitious and axillary shoots of three apple scion cultivars in vitro. Journal of Horticultural Science, UK, v. 65 , n. 2, p. 113-121, 1990

STEEL, R.G.D., TORRIE, J.H. Principles and procedures of statistics - A biometrical approach. 2. ed., New York: Mcgraw-Hill Book, 1980. 633 p.

SHARMA, K.K., BHOJWANI, S.S., THORPE, T.A. Factors affecting high frequency differentiation of shoots and roots

from cotyledon explants of Brassica juncea 9L.) CZERN. Plant Science, Ireland, v. 66, p. 247-253, 1990.

SRISKANDARAJAH, S, SKIRVIN, R.M, ABU-QAOUD, H., KORBAN, S.S. Factors involved in shoot elongation and growth of adventitious and axillary shoots of three apple scion cultivars in vitro. Journal of Horticultural Science, UK, v. 65, n. 2, p. 113-121, 1990

STEEL, R.G.D., TORRIE, J.H. Principles and procedures of statistics - A biometrical approach. 2. ed., New York: Mcgraw-Hill Book, 1980. 633 p.

Ciência Rural, v. 30, n. 1, 2000. 